\title{
Acute kidney injury and inflammatory response of sepsis following cecal ligation and puncture in D-galactose-induced aging rats
}

This article was published in the following Dove Press journal:

Clinical Interventions in Aging

29 March 2017

Number of times this article has been viewed

\author{
Chao Liu',* \\ Jie $\mathrm{Hu}^{1, *}$ \\ Zhi Mao',* \\ Hongjun Kang' \\ Hui Liu' \\ Wanlei $\mathrm{Fu}^{2}$ \\ Yangfan $L v^{2}$ \\ Feihu Zhou' \\ 'Department of Critical Care \\ Medicine, Chinese People's \\ Liberation Army General Hospital, \\ Beijing, People's Republic of China; \\ 2Department of Pathology, Xinqiao \\ Hospital, Third Military Medical \\ University, Chongqing, People's \\ Republic of China \\ *These authors contributed equally \\ to this work
}

\begin{abstract}
Background: Recently, the D-galactose (D-gal)-induced mimetic aging rat model has been widely used in studies of age-associated diseases, which have shown that chronic D-gal exposure induces premature aging similar to natural aging in rats. With the increasing rate of sepsis in the geriatric population, an easy-access animal model for preclinical studies of elderly sepsis is urgently needed. This study investigates whether a sepsis model that is established in D-galinduced aging rats can serve as a suitable model for preclinical studies of elderly patients with sepsis.
\end{abstract}

Objective: To investigate the acute kidney injury (AKI) and inflammatory response of sepsis following cecal ligation and puncture (CLP) in D-gal-induced aging rats.

Methods: Twelve-week-old male Sprague Dawley rats were divided into low-dose D-gal (L D-gal, $125 \mathrm{mg} / \mathrm{kg} / \mathrm{d}$ ), high-dose D-gal (H D-gal, $500 \mathrm{mg} / \mathrm{kg} / \mathrm{d}$ ), and control groups. After daily subcutaneous injection of D-gal for 6 weeks, the CLP method was used to establish a sepsis model.

Results: The mortality was $73.3 \%, 40 \%$, and $33.3 \%$ in the H D-gal, L D-gal, and control groups, respectively. Blood urea nitrogen, creatinine, plasma neutrophil gelatinase-associated lipocalin, interleukin-6, interleukin-10, and tumor necrosis factor- $\alpha$ were markedly increased in the H D-gal group after establishment of the sepsis model (H D-gal vs control, $P<0.05$ at $12 \mathrm{~h}$ and $24 \mathrm{~h}$ post-CLP). The rate of severe AKI (RIFLE-F) at $24 \mathrm{~h}$ post-CLP was $43 \%$ for both the control and L D-gal groups and $80 \%$ for the $\mathrm{H}$ D-gal group.

Conclusion: High-dose-D-gal-induced aging rats are more likely to die from sepsis than are young rats, and probably this is associated with increased severity of septic AKI and an increased inflammatory response. Therefore, use of the high-dose-D-gal-induced aging rat model of sepsis for preclinical studies can provide more useful information for the treatment of sepsis in elderly patients.

Keywords: acute kidney injury, inflammatory response, cecal ligation and puncture, D-galactose, aging rat

\section{Introduction}

Sepsis is a major health care concern, especially in the elderly population. ${ }^{1}$ Over $60 \%$ of sepsis cases occur in patients older than 65 years, and both sepsis-related complications and mortality rates significantly increase as age advances. ${ }^{2}$ Unfortunately, most basic research on sepsis has been conducted using young animals, and these models have not produced useful pharmacological therapies for clinical translation. ${ }^{3}$ This gap in clinical applicability exists because most mice used in sepsis research are less than 3 months old, which is comparable to a person under 20 years of age and does not
Correspondence: Feihu Zhou

Department of Critical Care Medicine,

Chinese People's Liberation Army

General Hospital, 28 Fu-Xing

Road, Beijing 100853, People's

Republic of China

$\mathrm{Tel}+861066938148$

Fax +861088219862

Email feihuzhou30I@I26.com
Clinical Interventions in Aging 2017:12 593-602

593

Dovepress

http://dx.doi.org/10.21 477/CIA.SI 32277 (c) (1) (2) 2017 Liu et al. This work is published and licensed by Dove Medical Press Limited. The full terms of this license are available at https:///www.dovepress.com/terms.php
and incorporate the Creative Commons Atribution - Non Commercial (unported, v3.0) License (http:///creativecommons.org/licenses/by-nc/3.0/). By accessing the work you hereby accept the Terms. Non-commercial uses of the work are permitted without any furcher permission from Dove Medical Press Limited, provided the work is properly attributed. For permission




reflect the unique pathophysiology of sepsis in the elderly., Several studies have suggested that development of aged animal models for sepsis research would be valuable, ${ }^{6-8}$ as this would provide useful information on the condition in elderly patients. Information gained from such models would also aid in the development of novel adjuvant treatments. However, the high cost and time investment required to utilize aged animals create limitations. Therefore, the establishment of an easily created and clinically relevant animal model of elderly sepsis for use in preclinical studies of new therapeutic agents is needed.

Recently, D-galactose (D-gal)-induced aged rodents have been widely used in studies of age-associated disease, especially neurological disease. ${ }^{9,10}$ Studies have confirmed that chronic D-gal exposure induces premature aging similar to natural aging in rats. ${ }^{11-13}$ Therefore, it is of interest to investigate whether a sepsis model that is established in D-gal-induced aging rats can serve as a suitable model for preclinical studies of elderly patients with sepsis.

In this research, our aim is to investigate the acute kidney injury (AKI) and inflammatory response of sepsis following cecal ligation and puncture (CLP) in D-gal-induced aging rats. Based on the current literature, we divided 12-weekold male Sprague Dawley rats into a low-dose D-gal group (125 mg/kg/d), ${ }^{14}$ a high-dose D-gal group (500 mg/kg/d), ${ }^{15}$ and a control group. After daily subcutaneous injection of D-gal for 6 weeks, the CLP method was used to establish a sepsis model. Mortality, oxidative damage condition, physiologic parameters, serum biochemical parameters, and kidney histology were compared among the three groups. We also compared microRNA-155 (miRNA-155) expression among the three groups. miRNA-155 is a class of small noncoding RNA molecules that play critical roles in innate immune responses and inflammation, and it has been found to be upregulated in macrophages following stimulation by a broad range of inflammatory mediators. ${ }^{16,17}$ Therefore, we measured this biomarker to detect differences in the innate immune responses and inflammation among the different groups.

\section{Materials and methods}

\section{Animals and treatments}

Twelve-week-old male Sprague Dawley rats were purchased from the animal center at the Chinese People's Liberation Army (PLA) General Hospital (Beijing, People's Republic of China). All of the animal procedures were approved by the Institutional Animal Care and Use Committee at the Chinese PLA General Hospital and Military Medical College. Animals were housed in a temperature-controlled room $\left(22^{\circ} \mathrm{C} \pm 1^{\circ} \mathrm{C}\right)$ with a 12-h light-dark cycle and had free access to food and tap water. The rats were adapted to the feeding regimen for at least 1 week before being subjected to the experiments. All of the experimental studies were conducted in accordance with "Recommendations on the Establishment of Animal Experimental Guidelines", and ethical procedures were conducted under Reduction, Replacement, and Refinement (the 3 Rs rule). The body weights of the rats were recorded every week. D-gal was dissolved in $0.9 \%$ saline at a concentration of either $25 \mathrm{mg} / \mathrm{mL}$ or $100 \mathrm{mg} / \mathrm{mL}$ before use.

The experimental and control groups were organized as follows: 1) low-dose D-gal-induced (L D-gal) mimetic aging group ( $\mathrm{n}=24), 2$ ) high-dose D-gal-induced (H D-gal) mimetic aging group ( $n=24)$, and 3 ) control group $(n=24)$. The L D-gal and $\mathrm{H}$ D-gal groups received daily subcutaneous injection of D-gal (Sigma, St Louis, MA, USA) at a dose of $125 \mathrm{mg} / \mathrm{kg}$ and $500 \mathrm{mg} / \mathrm{kg}$, respectively, for 6 weeks. The control group was given a daily injection of vehicle ( $0.9 \%$ saline) over the same period. After this injection procedure, each group was divided into three subgroups, with rats sacrificed pre-CLP $(n=7), 12$ h post-CLP $(n=7)$, or 24 h post-CLP $(n=10)$ for blood and tissue collection.

\section{Surgical procedure}

Sepsis was induced by CLP. The rats were anesthetized via intraperitoneal injection of pentobarbital sodium $(50 \mathrm{mg} / \mathrm{kg})$, and a $2-\mathrm{cm}$ ventral midline abdominal incision was made. The cecum was then exposed and ligated with a predetermined $25 \%$ length of cecum and a double puncture was made through both sides with an $18 \mathrm{G}$ needle. A small amount of fecal material was extruded from the puncture site, and the cecum was then returned to the abdominal cavity. The incision was closed in layers using 4-0 silk suture. All of the rats were resuscitated with subcutaneous administration of $20 \mathrm{~mL} / \mathrm{kg}$ lactated Ringer's solution immediately after surgery and returned to their cages, where they were provided access to food and water ad libitum. Sham-operated rats were treated as described above except for subjection to CLP.

\section{Lethality studies}

Forty-five rats from each of the three groups (L D-gal, $\mathrm{H}$ D-gal, and control) and five rats from the sham group were used for lethality studies. Following CLP or the sham procedure, the animals were allowed to recover from anesthesia and then observed for 7 days. The time to death after surgery for each animal was noted and recorded.

\section{Measurements of physiologic parameters}

Three physiologic parameters were measured to characterize sepsis progression in the groups. Systolic blood pressure 
and heart rate were measured with a tail cuff pressure transducer and polygraph (Kent Scientific CODA 20884, Torrington, CT, USA) pre-CLP and $24 \mathrm{~h}$ post-CLP. Rectal temperatures were recorded with a digital thermometer (Yuwell YT 305, Jiangsu, People's Republic of China) while animals were maintained at room temperature and again at $24 \mathrm{~h}$ post-CLP.

\section{Measurements of serum biochemical parameters}

Blood samples were drawn from the abdominal aorta preCLP, $12 \mathrm{~h}$ post-CLP, and $24 \mathrm{~h}$ post-CLP. Isolated plasma was maintained at $-80^{\circ} \mathrm{C}$ for subsequent measurements of blood urea nitrogen $(\mathrm{BUN})$, creatinine $(\mathrm{Cr})$, superoxide dismutase (SOD), malondialdehyde (MDA), neutrophil gelatinase-associated lipocalin (NGAL), interleukin (IL)-6, interleukin (IL)-10, tumor necrosis factor- $\alpha$ (TNF- $\alpha$ ), and microRNA-155 (miRNA-155). BUN was detected with a urea enzymatic assay kit (C013-2, Jiancheng Bioengineering Institute, Nanjing, People's Republic of China), and Cr was detected with a creatinine enzymatic assay kit (C011-1). SOD, MDA, and NGAL were measured with an enzymelinked immunosorbent assay (ELISA) kit following the manufacturer's instructions (Denley Dragon Wellscan MK 3, Thermo, Vantaa, Finland). Concentrations of IL-6, IL-10, and TNF- $\alpha$ were quantified using a Luminex screening rat magnetic assay (LXSARM-04, R\&D, Minneapolis, MN, USA).

\section{Extraction and measurement of miRNA}

TRIzol reagent was used for the isolation of total RNA from plasma samples and reverse transcription reactions using miRcute miRNA First-strand cDNA Synthesis kits (cat. no DP501, Tiangen, Garze, People's Republic of China) following the manufacturer's instructions. miRNA155 expression was quantified by real-time polymerase chain reaction (qRT-PCR) using SYBR Green (BioTNT, Shanghai, People's Republic of China) with Rnu6B small nuclear RNA as the internal normalized reference (forward, 5'-CTCGCTTCGGCAGCACA-3' and reverse, 5'-AACGCTTCACGAATTTGCGT-3'). qRT-PCR reactions were performed using a Roche Light Cycler 480 Real-Time PCR system with the following protocol: $95^{\circ} \mathrm{C}$ for 15 minutes followed by 40 cycles of denaturation at $95^{\circ} \mathrm{C}$ for 15 seconds and annealing/extension at $60^{\circ} \mathrm{C}$ for 60 seconds. All of the reactions were performed in triplicate. The sequence of the miRNA-155 probe rno-miR-155-5p, rat, was UUAAUGC UAAUUGUGAUAGGGGU (Applied Biosystems, Foster, CA, USA).

\section{Evaluation of AKI severity and kidney histology}

AKI severity was assessed based on the serum $\mathrm{Cr}$ portion of the RIFLE criteria, ${ }^{18-20}$ which classifies risk (R), injury (I), and failure $(\mathrm{F})$ on the basis of maximum $\mathrm{Cr}$ increases of $150 \%$, $200 \%$, and $300 \%$, respectively, at $12 \mathrm{~h}$ and $24 \mathrm{~h}$ post-CLP.

Organ sections $(5 \mu \mathrm{m})$ were fixed in $10 \%$ formalin, embedded in paraffin, and stained with periodic acid-Schiff reagent and hematoxylin and eosin $(\mathrm{HE})$. All of the tissue sections were independently evaluated in a blinded manner under a light microscope by two investigators. The morphological changes indicative of AKI were considered the loss of brush border, the vacuolization of tubular epithelial cells, and the presence of intratubular debris. ${ }^{19}$

\section{Statistical analysis}

Analysis was performed using IBM SPSS Statistics 21.0 software (IBM Corporation, Armonk, NY, USA). Data are presented as the means \pm standard error or medians with interquartile ranges where appropriate. One-way analysis of variance and Student's $t$-test were used to compare the means of continuous variables with assured normality; otherwise, the Mann-Whitney $U$ test was used. Categorical variables are expressed as proportions and were compared using the $\chi^{2}$ test. Survival analysis was assessed with Kaplan-Meier statistics and compared using the log-rank test. A probability value less than 5\% was considered statistically significant. GraphPad Prism (Graph Pad Software, San Diego, CA, USA) was used for all analyses.

\section{Results \\ Effects on mortality}

Figure 1 shows that the H D-gal group exhibited high mortality $(73.3 \%)$ after the CLP sepsis model was established.

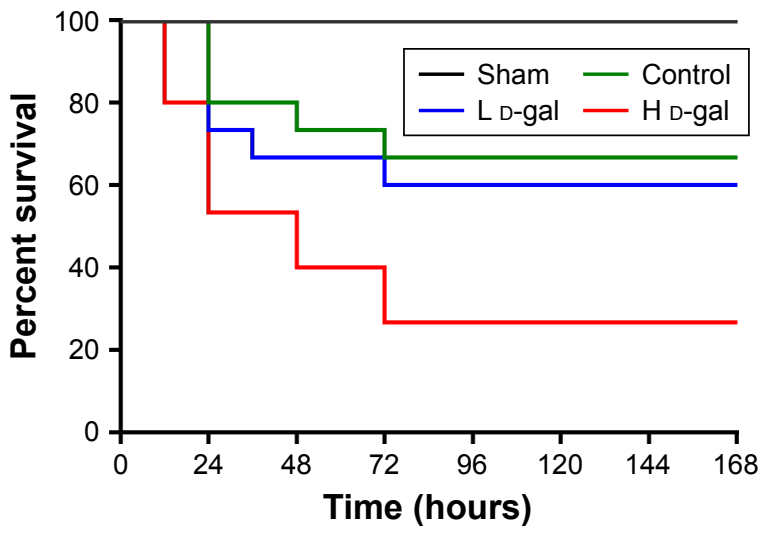

Figure I Survival of septic rats from the three groups.

Notes: H D-gal vs control $P=0.022$; $H$ D-gal vs $L$ D-gal $P=0.059$; L D-gal vs control $P=0.689$.

Abbreviations: D-gal, D-galactose; H D-gal, high-dose D-gal; L D-gal, low-dose D-gal. 
A significant difference $(P=0.022)$ was found between this group and the control group (mortality $=33.3 \%$ ). Mortality in the L D-gal group was 40\%; although this value was markedly lower than that of the H D-gal group, no significant difference between groups was found $(P=0.059)$. There was also no significant difference between the L D-gal and control groups $(P=0.689)$.

\section{Effects on oxidative damage}

MDA level and SOD activity were measured before CLP surgery, and significant differences were found among the three groups (H D-gal vs control, $P<0.01$ for MDA and SOD; L D-gal vs control, $P<0.01$ for MDA and SOD; H D-gal vs L D-gal, $P=0.017$ for MDA, $P=0.034$ for SOD; Figure 2).

\section{Effects on renal function}

$\mathrm{Cr}$ and BUN levels are shown in Figure $3 \mathrm{~A}$ and $\mathrm{B}$. The results show that renal function was severely damaged in the $\mathrm{H}$ D-gal group after CLP (H D-gal vs control, $P=0.002$ for $\mathrm{Cr}$ and $P=0.017$ for BUN at $12 \mathrm{~h}$ post-CLP, $P=0.006$ for $\mathrm{Cr}$ and $P=0.004$ for BUN at $24 \mathrm{~h}$ post-CLP; L D-gal vs control, $P=0.659$ for $\mathrm{Cr}$ and $P=0.365$ for BUN at $12 \mathrm{~h}$ post-CLP, $P=0.496$ for $\mathrm{Cr}$ and $P=0.503$ for BUN at $24 \mathrm{~h}$ post-CLP; $\mathrm{H}$ D-gal vs L D-gal, $P=0.010$ for $\mathrm{Cr}$ and $P=0.160$ for $\mathrm{BUN}$ at $12 \mathrm{~h}$ post-CLP, $P=0.042$ for $\mathrm{Cr}$ and $P=0.028$ for $\mathrm{BUN}$ at $24 \mathrm{~h}$ post-CLP).

At $12 \mathrm{~h}$ post-CLP, AKI morbidity was $86 \%$ for the control and L D-gal groups and $100 \%$ for the H D-gal group (Figure 3C). The rate of severe AKI (RIFLE-F) at $24 \mathrm{~h}$ postCLP was $43 \%$ for the control and L D-gal groups and $80 \%$ for the H D-gal group (Figure 3D). No significant differences were found among the groups.

\section{Effects on a biomarker of AKI}

Plasma NGAL is a biomarker of AKI. NGAL levels were markedly increased in the H D-gal group after CLP (H D-gal vs control, $P=0.021$ at $12 \mathrm{~h}$ post-CLP and $P=0.001$ at $24 \mathrm{~h}$ post CLP; L D-gal vs control, $P=0.472$ at $12 \mathrm{~h}$ post-CLP and $P=0.043$ at $24 \mathrm{~h}$ post CLP; H D-gal vs L D-gal, $P=0.142$ at $12 \mathrm{~h}$ post-CLP and $P=0.036$ at $24 \mathrm{~h}$ post CLP; Figure $4 \mathrm{~A}$ ).

\section{Effects on inflammatory response}

Plasma levels of IL-6 (Figure 4B), IL-10 (Figure 4C), and TNF- $\alpha$ (Figure 4D) were markedly increased in all three groups after CLP. All cytokine levels in the H D-gal group were significantly different than those in the L D-gal and control groups (H D-gal vs control, $P<0.01$ for Il-6, IL-10 and TNF- $\alpha$ at $12 \mathrm{~h}$ and $24 \mathrm{~h}$ post-CLP; H D-gal vs L D-gal, $P<0.05$ for Il-6, IL-10 and TNF- $\alpha$ at $12 \mathrm{~h}$ and $24 \mathrm{~h}$ postCLP). The cytokine levels in the L D-gal group were also significantly different than those in the control group $(P<0.05$ for Il-6, IL-10 and TNF- $\alpha$ at $12 \mathrm{~h}$ and $24 \mathrm{~h}$ post-CLP).

\section{Effects on miRNA-I55 expression}

miRNA-155 expression increased after D-gal injection in a dose-dependent manner (H D-gal vs control, $P<0.01$; L D-gal vs control, $P<0.01$; H D-gal vs L D-gal, $P<0.01$; Figure 4). Expression also increased after CLP (H D-gal vs control, $P<0.01$ at $12 \mathrm{~h}$ and $24 \mathrm{~h}$ post-CLP; L D-gal vs control, $P<0.01$ at $12 \mathrm{~h}$ and $24 \mathrm{~h}$ post-CLP; H D-gal vs L D-gal, $P<0.01$ at $12 \mathrm{~h}$ and $24 \mathrm{~h}$ post-CLP; Figure 5).

\section{Effects on kidney histology}

Figure 6 shows kidney histology obtained using HE and PAS staining under light microscopy with an original magnification of $\times 400$. Loss of brush border, vascular degeneration of tubular epithelial cells, and dilation of glomerular capillary were most prominent in the H D-gal group.

\section{Effects on physiologic parameters}

Systolic pressure, heart rate, rectal temperature, and body weight were measured for all three groups (Table 1).
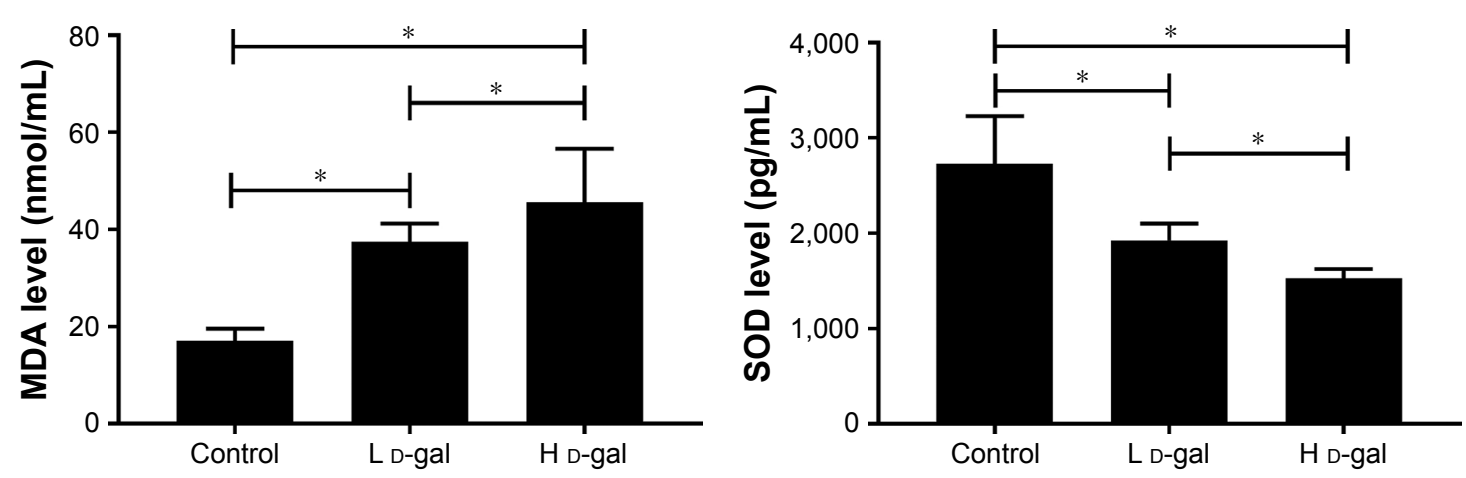

Figure 2 Serum MDA and SOD levels in the three groups.

Notes: MDA and SOD were measured before CLP. ${ }^{*} P<0.05$.

Abbreviations: CLP, cecal ligation and puncture; D-gal, D-galactose; H D-gal, high-dose D-gal; L D-gal, low-dose D-gal; MDA, malondialdehyde; SOD, superoxide dismutase. 
A

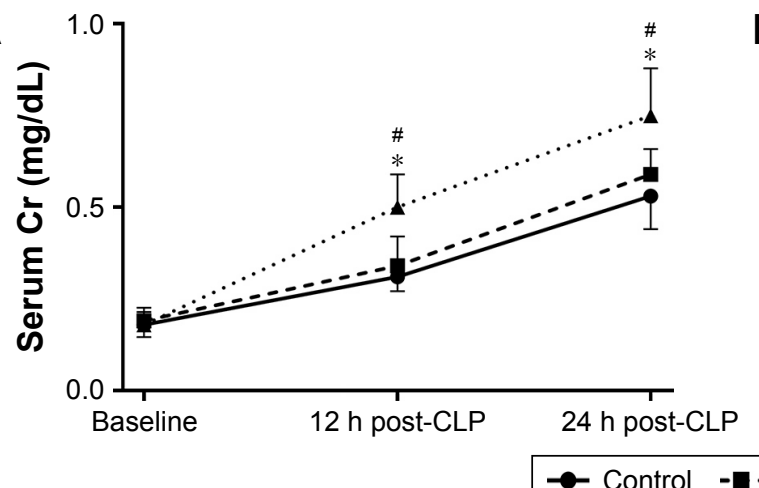

C

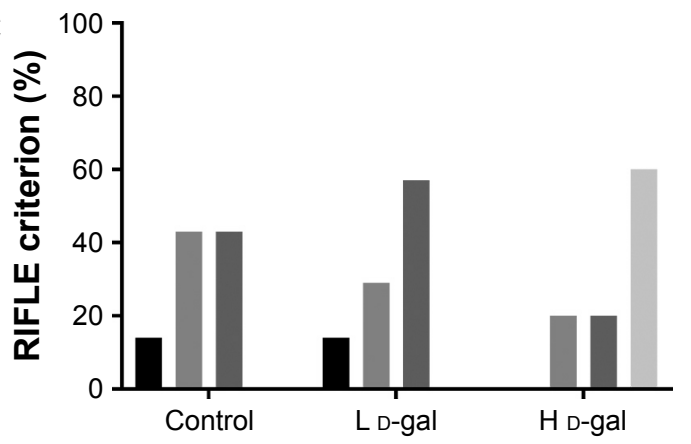

B

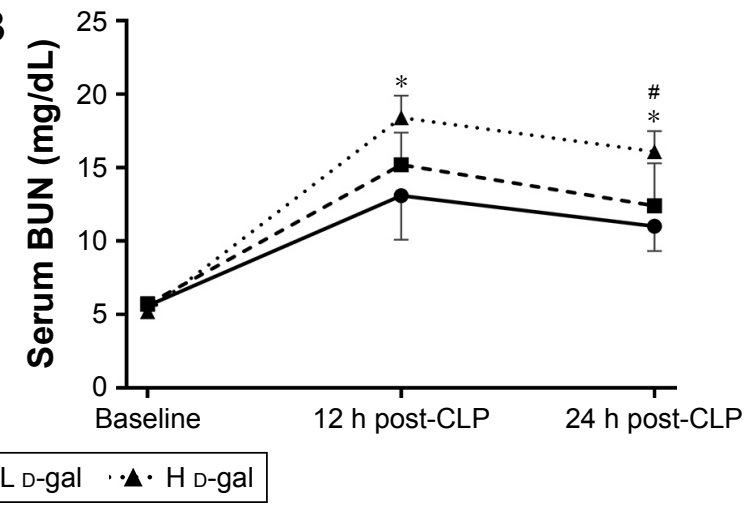

D

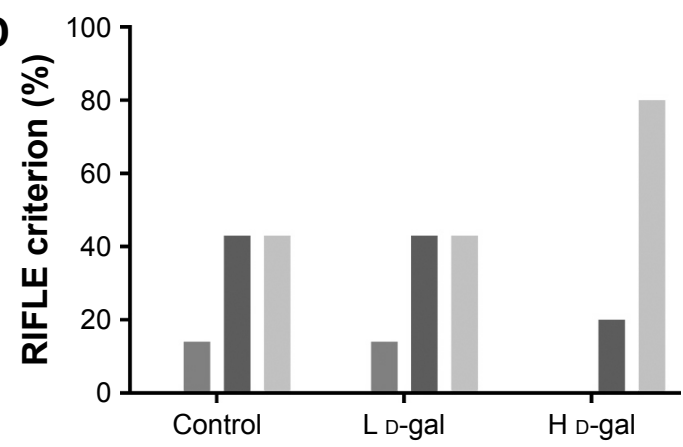

NOAKI $\quad \mathrm{R} \quad \mathrm{I} \quad \mathrm{F}$

Figure 3 Renal function in septic rats of the three groups.

Notes: (A) Serum Cr concentration. (B) BUN concentration. (C) Severity of AKI 12 h post-CLP. (D) Severity of AKI $24 \mathrm{~h}$ post-CLP. AKI was measured based on RIFLE categories. R, I, F = AKI RIFLE classes risk (creatinine change, 150\%-199\%), injury (creatinine change, 200\%-299\%), and failure (creatinine change, $\geq 300 \%$ ). Data are shown as the mean \pm standard error. ${ }^{* P}<0.05$ compared with the control group. ${ }^{*} P<0.05$ compared with the $L \mathrm{D}$-gal group.

Abbreviations: CLP, cecal ligation and puncture; D-gal, D-galactose; H D-gal, high-dose D-gal; L D-gal, low-dose D-gal; Cr, creatinine; BUN, blood urea nitrogen; AKI, acute kidney injury.
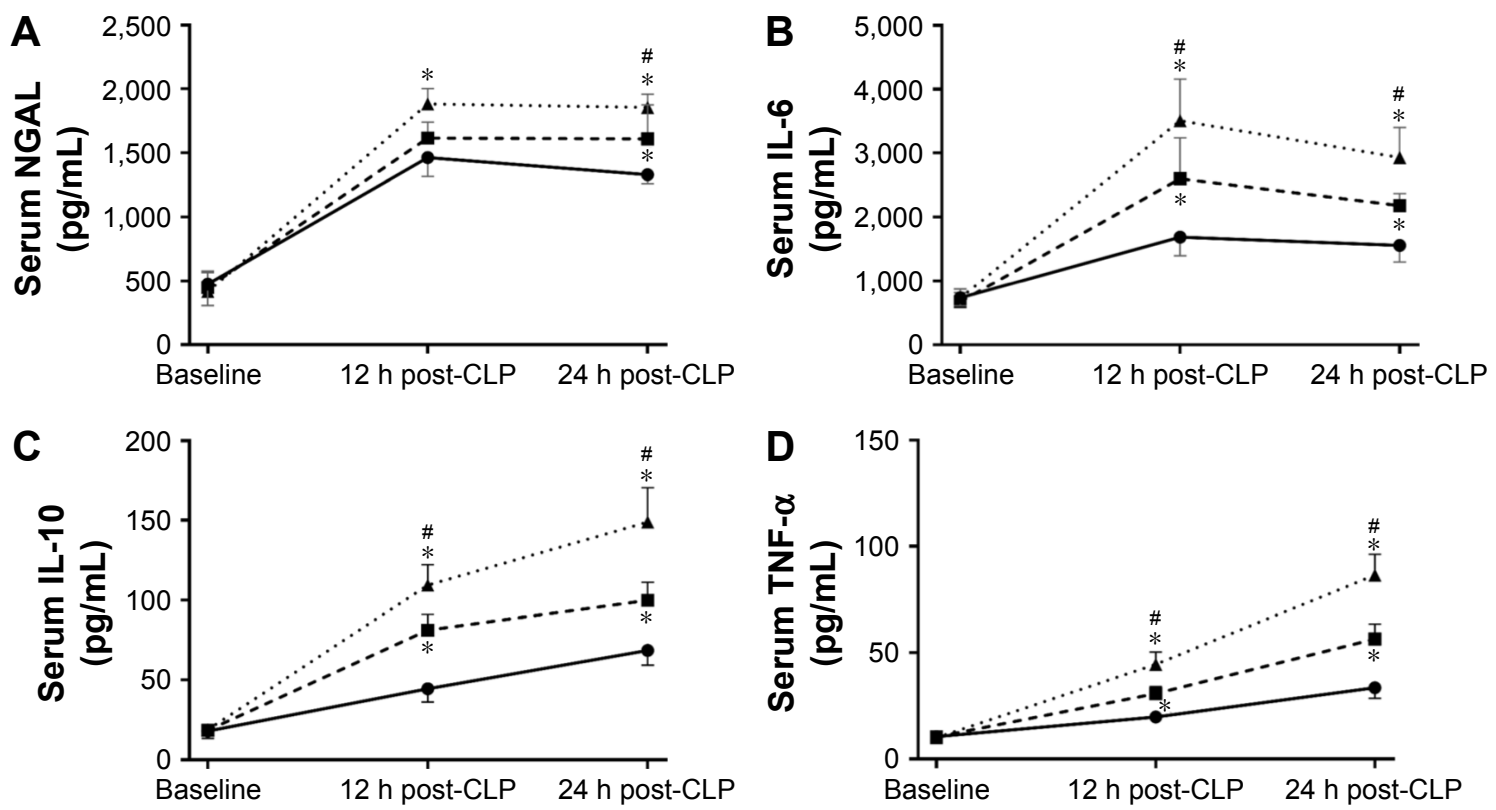

Control - $\mathbf{-} \cdot \mathrm{L}$ D-gal $\cdot \mathbf{\Delta} \cdot \mathrm{H}$ D-gal

Figure 4 Plasma cytokine levels in septic rats of the three groups.

Notes: (A) Plasma NGAL. (B) Plasma IL-6. (C) Plasma IL-10. (D) Plasma TNF- $\alpha$. $* P<0.05$ compared with the control group. ${ }^{*} P<0.05$ compared with the L D-gal group.

Abbreviations: CLP, cecal ligation and puncture; D-gal, D-galactose; H D-gal, high-dose D-gal; L D-gal, low-dose D-gal; NGAL, neutrophil gelatinse-associated lipocalin; IL, interleukin; TNF, tumor necrosis factor. 


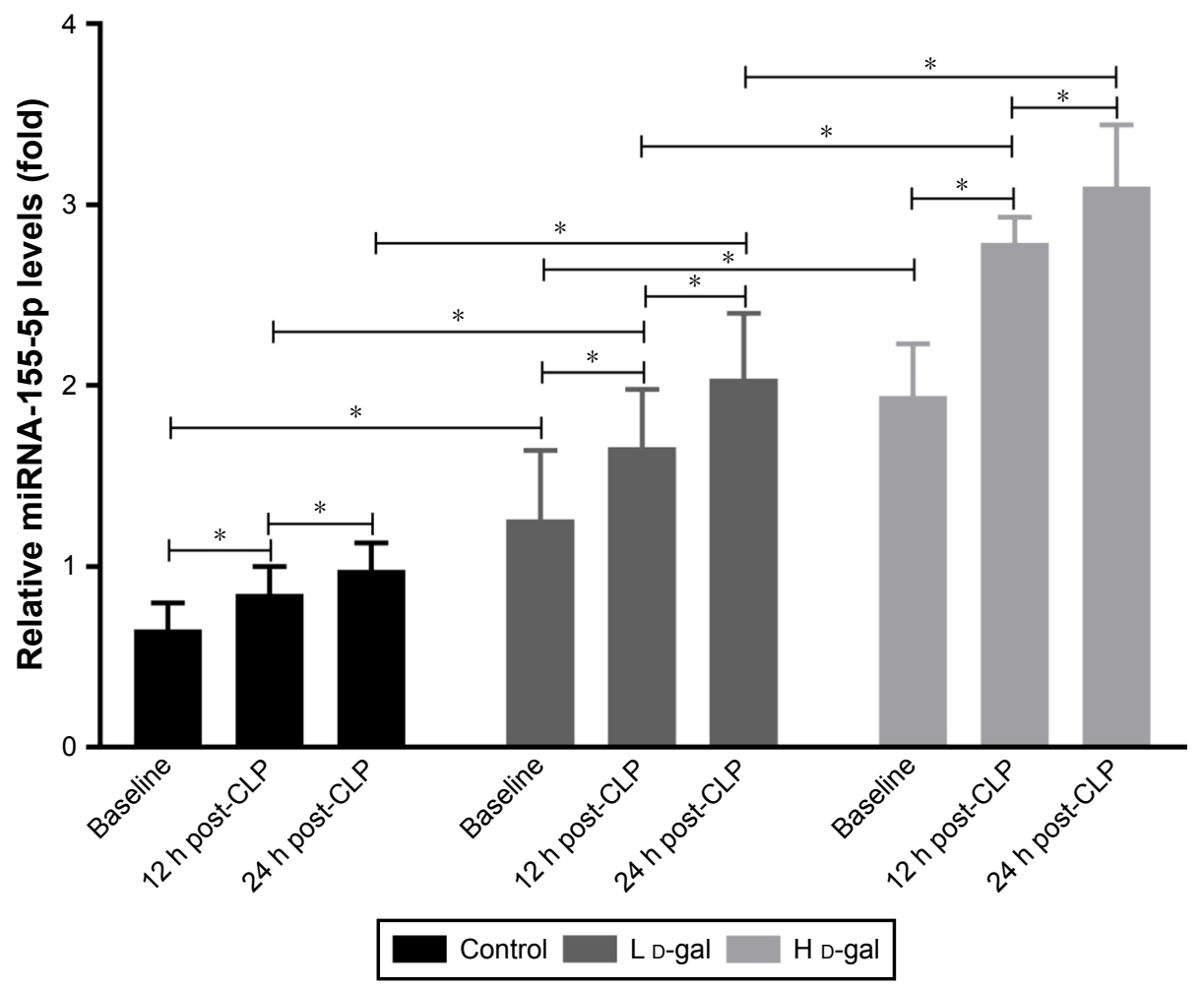

Figure 5 Expression of miRNA-155 in septic rats of the three groups.

Note: $* P<0.05$.

Abbreviations: CLP, cecal ligation and puncture; D-gal, D-galactose; H D-gal, high-dose D-gal; L D-gal, low-dose D-gal.

The results indicated that the H D-gal group was more likely to suffer severe septic shock (lower systolic pressure and heart rate) and hypothermia after CLP than were the L D-gal and control groups. Although a low body weight was observed in the H D-gal group, no significant difference was found between this group and either of the L D-gal and control groups. There was also no significant difference between the L D-gal and control groups.

\section{Discussion}

This study describes the acute kidney injury and inflammatory response of sepsis following cecal ligation and puncture in D-gal-induced aging rats. The results showed that among the three groups the H D-gal group was most likely to suffer from severe septic shock and hypothermia, and this group exhibited high mortality, impaired renal function, severity of septic AKI, increased inflammatory response, and enhanced miRNA-155 expression. Therefore, use of this model for preclinical studies can provide useful information for the treatment of sepsis in elderly patients.

In recent decades, the prevalence of elderly patients suffering from sepsis has increased, which has been accompanied by increased mortality. ${ }^{2}$ Unfortunately, efforts to develop and gain regulatory approval for therapeutic agents as adjuvant treatments for sepsis have been unsuccessful. ${ }^{3}$ The lack of success in translating laboratory results to the clinical realm can be attributed to inadequate animal models. ${ }^{1}$ One way to improve such success is to use aged mice. Another improvement is the use of "humanized" mice, which contain a complete lineage of human innate and adaptive immune system cells. ${ }^{21}$ However, both of these improvements are time-consuming and expensive and are therefore unlikely to be widely adopted. ${ }^{3,8}$ As such, there is an urgent need for the creation of an experimental animal model that can be used in preclinical studies for the geriatric population.

Compared with healthy animals, animals chronically treated with D-gal display shortened life span, cognitive dysfunction, neurodegeneration, and impaired immune responses, which resembles natural aging. ${ }^{22,23}$ Recently, studies focused on the roles of galactose in cellular senescence have shown that the mechanisms underlying D-gal-induced aging likely involve glucose and 1ipid metabolic disorders, increased oxidative damage, the accumulation of advanced glycation end products, impaired elimination of abnormal substances, accelerated cell apoptosis, and enhanced insulin resistance..$^{22,24}$ The effects produced by D-gal differ with 

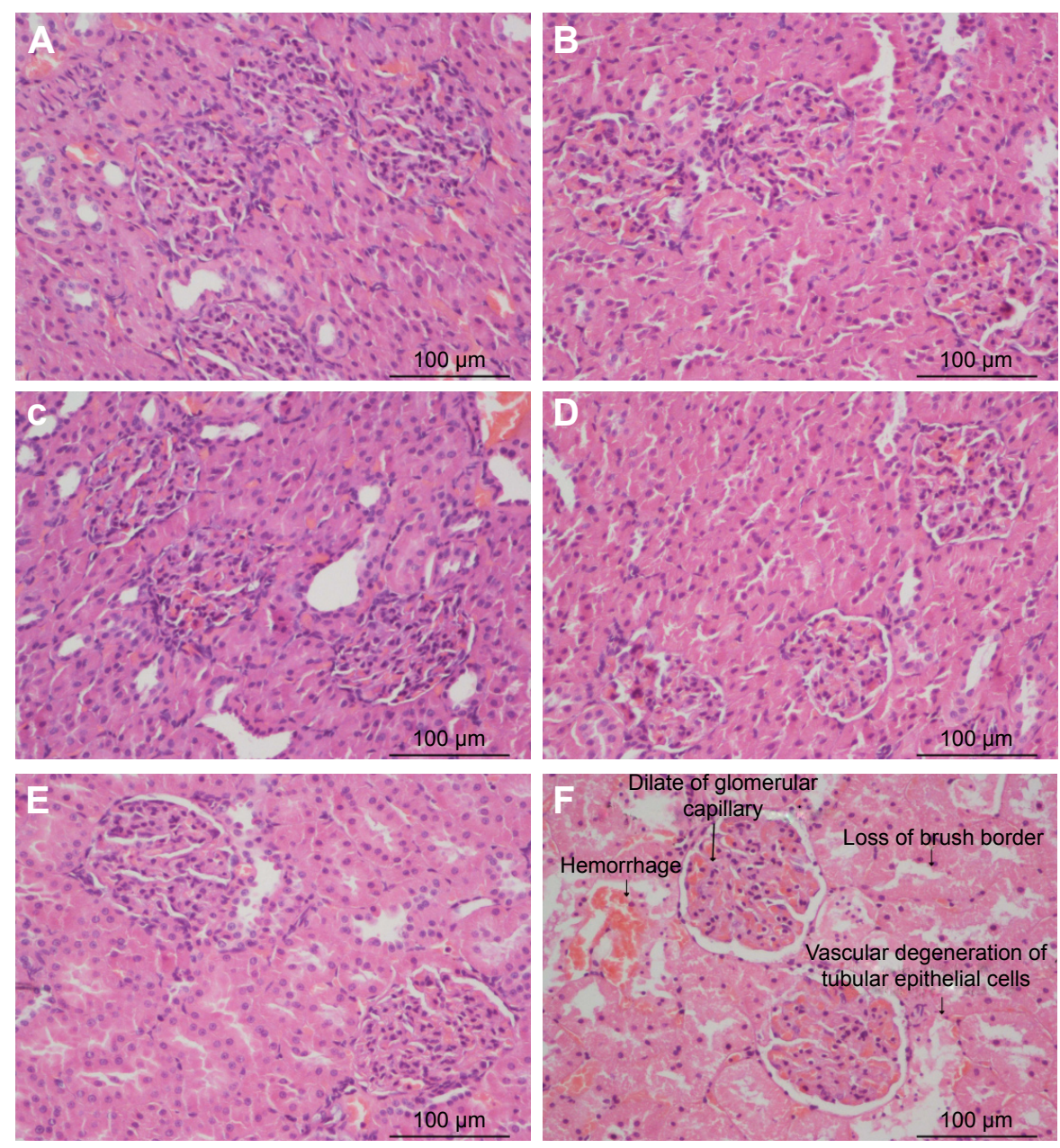

Figure 6 Kidney histopathology in septic rats of the three groups.

Notes: (A) Control group $12 \mathrm{~h}$ post-CLP. (B) Control group $24 \mathrm{~h}$ post-CLP. (C) L D-gal group $12 \mathrm{~h}$ post-CLP. (D) L D-gal group $24 \mathrm{~h}$ post-CLP. (E) H D-gal group $12 \mathrm{~h}$ post-CLP. (F) H D-gal group $24 \mathrm{~h}$ post-CLP.

Abbreviations: CLP, cecal ligation and puncture; D-gal, D-galactose; H D-gal, high-dose D-gal; L D-gal, low-dose D-gal.

dosage (varying between 50 and $1,250 \mathrm{mg} / \mathrm{kg} / \mathrm{d}$ ), age group (varying between 6 weeks and 6 months), and time interval (varying between 6 and 10 weeks). ${ }^{12}$ According to the literature, ${ }^{14,15}$ we induced aging in 12 -weeks-old rats using two different D-gal doses $(125 \mathrm{mg} / \mathrm{kg} / \mathrm{d}$ and $500 \mathrm{mg} / \mathrm{kg} / \mathrm{d})$. However, as the degree of D-gal-induced aging is both doseand time-dependent, the age-related relationship between
D-gal-induced aging rats and naturally aged rat is unknown. As this is the first study to establish the CLP model in the D-gal-induced aging rat, the optimal induced dose and duration need to be determined in future studies.

In the present study, we measured MDA level and SOD activity to estimate D-gal's effects. MDA is often measured as a major marker of lipid peroxidation in aged animals,

Table I Physiologic parameters of three groups

\begin{tabular}{|c|c|c|c|c|c|c|c|c|c|c|c|c|}
\hline \multirow[t]{2}{*}{$\begin{array}{l}\text { Measurement } \\
\text { time }\end{array}$} & \multicolumn{3}{|c|}{$\begin{array}{l}\text { Systolic blood pressure } \\
(\mathrm{mmHg})\end{array}$} & \multicolumn{3}{|c|}{ Heart rate (beats/min) } & \multicolumn{3}{|c|}{ Rectal temperature $\left({ }^{\circ} \mathrm{C}\right)$} & \multicolumn{3}{|c|}{ Body weight (g) } \\
\hline & Control & L D-gal & H D-gal & Control & L D-gal & H D-gal & Control & L D-gal & H D-gal & Control & L D-gal & H D-gal \\
\hline \multirow[t]{2}{*}{ Pre-CLP } & 140.5 & 143.4 & 139.6 & 332.7 & 343.4 & 337.4 & 37.3 & 37.1 & 37.3 & 502.8 & 493.8 & $480.5 \pm$ \\
\hline & \pm 78 & \pm 4.8 & \pm 6.7 & \pm 26.2 & \pm 15.1 & \pm 19.6 & \pm 0.4 & \pm 0.4 & \pm 0.5 & \pm 140 & $\pm 19.0 *$ & $16.4^{*}$ \\
\hline \multirow[t]{2}{*}{$24 \mathrm{~h}$ post-CLP } & 93.2 & 91.0 & 70.7 & 147.2 & 157.0 & 116.7 & 35.4 & 35.0 & 32.2 & & & \\
\hline & $\pm 8.8^{* *}$ & \pm 13.1 ** & $\pm 9.5 * * * * * * *$ & $\pm 24.6 * *$ & $\pm 21.4 * *$ & $\pm 20.3 *, * *, * * *$ & $\pm 0.6 * *$ & $\pm 1 . I^{* *}$ & $\pm 2.0 * * *, * * *$ & & & \\
\hline
\end{tabular}

Notes: $* P<0.05$ compared with control group. ${ }^{* * P}<0.05$ compared with the same group at pre-CLP. $* * * P<0.05$ compared with $L \mathrm{D}$-gal group. Data $p$ resented as mean \pm standard error.

Abbreviations: CLP, cecal ligation and puncture; D-gal, D-galactose; H D-gal, high dose of D-gal, L D-gal, low dose of D-gal. 
and SOD is an important enzyme in the antioxidant defense system that contributes to decreased tissue damage in aged animals during systemic inflammation. ${ }^{25,26}$ Our results showed markedly increased MDA levels and significantly decreased SOD activity in the H D-gal group, consistent with changes previously reported in aged rats. ${ }^{12}$

Elderly patients are at the highest risk for AKI because of age-related changes in kidney function, multiple comorbidities, and frequent exposure to iatrogenic insults. ${ }^{27,28}$ In this study, we measured plasma $\mathrm{Cr}$, BUN, and NGAL and evaluated kidney histology in different groups. Because we did not collect urinary samples, potential changes in the urine were not evaluated. However, in our previous study, ${ }^{19}$ we measured plasma and urine AKI-related biomarkers and found that the changes of urine biomarkers were consistent with the changes in plasma biomarkers. Therefore, although the evidence to proof the severity of AKI is insufficient, ${ }^{29}$ the results of our experiment all suggest that AKI was more severe in the H D-gal group than in the other groups. The sepsis model created here may be valuable for experiments attempting to identify novel effective therapies for elderly sepsis patients with AKI.

Elderly patients clearly show elevated sepsis-induced systemic inflammatory responses. ${ }^{30-32}$ Experiments have also shown that the proinflammatory molecules TNF- $\alpha$ and IL-6 and the anti-inflammatory molecule IL-10 are significantly increased in aged animals compared with young animals. ${ }^{33-35}$ In our study, despite the lack of a direct comparison with aged rats, augmented expression of TNF- $\alpha$, IL-6, and IL-10 were observed in the H D-gal group, and this group accurately mimicked the progress of the inflammatory response in aged rats.

miRNA-155 was initially discovered as a proto-oncogene in lymphoma, ${ }^{36}$ and its effect on inflammation and immunity have recently been identified. ${ }^{37}$ miRNA-155 can exert proinflammatory actions through the suppression of negative regulators of the toll-like receptor 4 (TLR4) pathway, ${ }^{38}$ and its expression has been found to increase in the spleen in the lipopolysaccharide (LPS)-induced endotoxin shock model in mice. ${ }^{39}$ In the present study, the expression of miRNA-155 was significantly increased in the $\mathrm{H}$ D-gal group, which indicates that an amplified inflammation and immunity response occurred in this group.

Compared with young mice, aged mice exhibit more profound hypothermia after both CLP surgery and LPS injection. ${ }^{33}$ From the physiologic parameter results, we found that the H D-gal group was more likely to suffer severe septic shock (lower systolic pressure and heart rate) and hypothermia after CLP. A prior study in a rat model of sepsis showed that inducing mild hypothermia $\left(34^{\circ} \mathrm{C} \pm 0.5^{\circ} \mathrm{C}\right)$ during acute sepsis appeared to reduce some proinflammatory and oxidative responses. ${ }^{40}$ The earlier that hypothermia was induced, the longer that the septic rats survived. ${ }^{41}$ However, in the present study, the rats in the $\mathrm{H}$ D-gal group showed deep hypothermia $\left(32.2^{\circ} \mathrm{C} \pm 2.0^{\circ} \mathrm{C}\right) 24 \mathrm{~h}$ post-CLP, which increased the harmful impact of hypothermia and led to higher mortality. ${ }^{42}$ In patients with severe sepsis, hypothermia (body temperature $\leq 36.5^{\circ} \mathrm{C}$ ) has been associated with increased mortality and organ failure, ${ }^{43}$ and it may be an early clinical predictor of sepsis-induced immunosuppression. ${ }^{44}$ Whether sepsis-induced mortality can be decreased by regulation of body temperature requires further research.

Age-related changes in the immune system, otherwise known as immunosenescence, increase the vulnerability of the older adult to infection while decreasing his or her immune response. ${ }^{45,46}$ Although aging is crucial in sepsis, the impacts of aging on inflammation and immunosuppression remain unclear. ${ }^{47}$ One study investigated the relationship between inflammation and immunosuppression in aged patients and mice after sepsis and showed that compared with young septic patients and mice, elderly septic patients and mice presented prolonged serum IL-6 elevation, impaired CD4+ T-cell activation with increased expression of programmed death 1 (PD-1) and cytotoxic T-lymphocyte antigen 4 (CTLA-4), and impaired IL-2 production. ${ }^{47}$ In addition, the persistent inflammation and T-cell exhaustion might be associated with decreased survival in elderly patients and mice after sepsis. ${ }^{47}$ Another study that investigated the effects of aging on the immunopathological response to sepsis showed that splenic apoptosis was increased in aged septic mice compared with young septic mice. ${ }^{7}$ More attention should be given to the differences in the immune response between aged and young subjects in future research on sepsis in the elderly.

Although the present study is the first to establish a CLP model in the D-gal-induced aging rat, it has several limitations. First, although the $\mathrm{H}$ D-gal rats appeared to mimic naturally aged rats, we did not perform a direct comparison with naturally aged rats. Therefore, there may be differences between induced aged rats and naturally aged rats that could not be detected. Second, the degree of D-gal-induced aging is both dose- and time-dependent. We chose an inducing dose and duration based on the literature, but more experiments are needed to optimize these conditions. Third, although there have been reports of gender differences in inflammatory response and survival following sepsis, ${ }^{48}$ only male rats were used in this study. Therefore, it is necessary to 
perform experiments on female animals. Fourth, only renal function was evaluated in this study, and the functioning of other organs, such as the liver and lung, should be evaluated in future work. Fifth, urine volume or urinary AKI markers were not evaluated; these should be measured to reflect the severity of AKI in future experiments. Finally, we only examined a single strain of rats. It has been shown that both life span and genetic susceptibility to sepsis vary among animal strains, ${ }^{49}$ and therefore, it is unclear whether our results are generalizable.

\section{Conclusion}

Despite the above limitations, the D-gal-induced aging rat model of sepsis described here can be easily and conveniently established. The results demonstrate that the change of pathophysiology in the $\mathrm{H}$ D-gal group may mimic the progress of sepsis in elderly patients. Therefore, this model should serve as an important tool for minimizing the existing disconnect between preclinical animal studies and the clinical reality of sepsis. It is our hope that this model offers a platform for identifying effective therapeutic options for managing sepsis in the vulnerable geriatric population.

\section{Acknowledgments}

The authors would like to thank Xin Hu and Pan Hu for their kind assistance in statistical analysis and Shengmao Jiang for animal care and housing.

\section{Disclosure}

The authors report no conflicts of interest in this work.

\section{References}

1. Yang WL, Ma G, Zhou M, et al. Combined administration of human ghrelin and human growth hormone attenuates organ injury and improves survival in aged septic rats. Mol Med. 2016;22:124-135.

2. Starr ME, Saito H. Sepsis in old age: review of human and animal studies. Aging Dis. 2014;5(2):126-136.

3. Fink MP. Animal models of sepsis. Virulence. 2014;5(1):143-153.

4. Esmon CT. Why do animal models (sometimes) fail to mimic human sepsis? Crit Care Med. 2004;32(Suppl 5):S219-S222.

5. Rittirsch D, Hoesel LM, Ward PA. The disconnect between animal models of sepsis and human sepsis. J Leukoc Biol. 2007;81(1):137-143.

6. Hyde SR, Stith RD, McCallum RE. Mortality and bacteriology of sepsis following cecal ligation and puncture in aged mice. Infect Immun. 1990;58(3):619-624.

7. Turnbull IR, Clark AT, Stromberg PE, et al. Effects of aging on the immunopathologic response to sepsis. Crit Care Med. 2009;37(3): 1018-1023.

8. Maddens B, Vandendriessche B, Demon D, et al. Severity of sepsisinduced acute kidney injury in a novel mouse model is age dependent. Crit Care Med. 2012;40(9):2638-2646.

9. Yoo DY, Kim W, Lee CH, et al. Melatonin improves D-galactose-induced aging effects on behavior, neurogenesis, and lipid peroxidation in the mouse dentate gyrus via increasing pCREB expression. J Pineal Res. 2012;52(1):21-28.
10. Ali T, Badshah H, Kim TH, Kim MO. Melatonin attenuates D-galactoseinduced memory impairment, neuroinflammation and neurodegeneration via RAGE/NF-K B/JNK signaling pathway in aging mouse model. J Pineal Res. 2015;58(1):71-85.

11. Ho SC, Liu JH, Wu RY. Establishment of the mimetic aging effect in mice caused by D-galactose. Biogerontology. 2003;4(1):15-18.

12. Aydin S, Yanar K, Atukeren P, et al. Comparison of oxidative stress biomarkers in renal tissues of D-galactose induced, naturally aged and young rats. Biogerontology. 2012;13(3):251-260.

13. Cebe T, Atukeren P, Yanar K, et al. Oxidation scrutiny in persuaded aging and chronological aging at systemic redox homeostasis level. Exp Gerontol. 2014;57:132-140.

14. Huang HC, Zheng BW, Guo Y, et al. Antioxidative and neuroprotective effects of curcumin in an alzheimer's disease rat model cotreated with intracerebroventricular streptozotocin and subcutaneous D-Galactose. J Alzheimers Dis. 2016;52(3):899-911.

15. Du Z, Yang Q, Zhou T, et al. Dgalactoseinduced mitochondrial DNA oxidative damage in the auditory cortex of rats. Mol Med Rep. 2014; 10(6):2861-2867.

16. Wang ZH, Liang YB, Tang $\mathrm{H}$, et al. Dexamethasone down-regulates the expression of microRNA-155 in the livers of septic mice. PLoS One. 2013;8(11):e80547.

17. O'Connell RM, Taganov KD, Boldin MP, Cheng G, Baltimore D. MicroRNA-155 is induced during the macrophage inflammatory response. Proc Natl Acad Sci U S A. 2007;104(5):1604-1609.

18. Bellomo R, Ronco C, Kellum JA, Mehta RL, Palevsky P; Acute Dialysis Quality Initiative workgroup. Acute renal failure - definition, outcome measures, animal models, fluid therapy and information technology needs: the Second International Consensus Conference of the Acute Dialysis Quality Initiative (ADQI) Group. Crit Care. 2004; 8(4):R204-R212.

19. Zhou F, Peng ZY, Bishop JV, Cove ME, Singbartl K, Kellum JA. Effects of fluid resuscitation with $0.9 \%$ saline versus a balanced electrolyte solution on acute kidney injury in a rat model of sepsis. Crit Care Med. 2014;42(4):e270-e278.

20. Peng ZY, Wang HZ, Srisawat N, et al. Bactericidal antibiotics temporarily increase inflammation and worsen acute kidney injury in experimental sepsis. Crit Care Med. 2012;40(2):538-543.

21. Unsinger J, McDonough JS, Shultz LD, Ferguson TA, Hotchkiss RS Sepsis-induced human lymphocyte apoptosis and cytokine production in "humanized" mice. J Leukoc Biol. 2009;86(2):219-227.

22. Elzi DJ, Song M, Shiio Y. Role of galactose in cellular senescence. Exp Gerontol. 2016;73:1-4.

23. Zhou Y, Dong Y, Xu Q, et al. Mussel oligopeptides ameliorate cognition deficit and attenuate brain senescence in D-galactose-induced aging mice. Food Chem Toxicol. 2013;59:412-420.

24. Zhou YY, Ji XF, Fu JP, et al. Gene transcriptional and metabolic profile changes in mimetic aging mice induced by D-Galactose. PLoS One. 2015;10(7):e0132088.

25. Starr ME, Ueda J, Yamamoto S, Evers BM, Saito H. The effects of aging on pulmonary oxidative damage, protein nitration, and extracellular superoxide dismutase down-regulation during systemic inflammation. Free Radic Biol Med. 2011;50(2):371-380.

26. Uzun D, Korkmaz GG, Sitar ME, et al. Oxidative damage parameters in renal tissues of aged and young rats based on gender. Clin Interv Aging. 2013;8:809-815.

27. Chronopoulos A, Rosner MH, Cruz DN, Ronco C. Acute kidney injury in elderly intensive care patients: a review. Intensive Care Med. 2010;36(9):1454-1464.

28. Neild GH. Multi-organ renal failure in the elderly. Int Urol Nephrol. 2001;32(4):559-565.

29. Hu YM, Pai MH, Yeh CL, Hou YC, Yeh SL. Glutamine administration ameliorates sepsis-induced kidney injury by downregulating the highmobility group box protein-1-mediated pathway in mice. Am J Physiol Renal Physiol. 2012;302(1):F150-F158.

30. Krabbe KS, Pedersen M, Bruunsgaard H. Inflammatory mediators in the elderly. Exp Gerontol. 2004;39(5):687-699. 
31. Bouza C, Lopez-Cuadrado T, Amate-Blanco JM. Characteristics, incidence and temporal trends of sepsis in elderly patients undergoing surgery. Br J Surg. 2016;103(2):e73-e82.

32. Chou HL, Han ST, Yeh CF, et al. Systemic inflammatory response syndrome is more associated with bacteremia in elderly patients with suspected sepsis in emergency departments. Medicine (Baltimore). 2016;95(49):e5634.

33. Saito H, Sherwood ER, Varma TK, Evers BM. Effects of aging on mortality, hypothermia, and cytokine induction in mice with endotoxemia or sepsis. Mech Ageing Dev. 2003;124(10-12):1047-1058.

34. Okamura D, Starr ME, Lee EY, Stromberg AJ, Evers BM, Saito H. Agedependent vulnerability to experimental acute pancreatitis is associated with increased systemic inflammation and thrombosis. Aging Cell. 2012;11(5):760-769.

35. Starr ME, Hu Y, Stromberg AJ, et al. Gene expression profile of mouse white adipose tissue during inflammatory stress: age-dependent upregulation of major procoagulant factors. Aging Cell. 2013;12(2): 194-206.

36. Tam W, Ben-Yehuda D, Hayward WS. bic, a novel gene activated by proviral insertions in avian leukosis virus-induced lymphomas, is likely to function through its noncoding RNA. Mol Cell Biol. 1997;17(3): 1490-1502.

37. Faraoni I, Antonetti FR, Cardone J, Bonmassar E. miR-155 gene: a typical multifunctional microRNA. Biochim Biophys Acta. 2009; 1792(6):497-505.

38. Billeter AT, Hellmann J, Roberts H, et al. MicroRNA-155 potentiates the inflammatory response in hypothermia by suppressing IL-10 production. FASEB J. 2014;28(12):5322-5336.

39. Tili E, Michaille JJ, Cimino A, et al. Modulation of miR-155 and miR-125b levels following lipopolysaccharide/TNF-alpha stimulation and their possible roles in regulating the response to endotoxin shock. J Immunol. 2007;179(8):5082-5089.
40. Leon K, Moisan C, Amerand A, Poupon G, L'Her E. Effect of induced mild hypothermia on two pro-inflammatory cytokines and oxidative parameters during experimental acute sepsis. Redox Rep. 2013;18(3): 120-126.

41. Leon K, Pichavant-Rafini K, Ollivier H, Monbet V, L'Her E. Does induction time of mild hypothermia influence the survival duration of septic rats? Ther Hypothermia Temp Manag. 2015;5(2):85-88.

42. Weinrauch V, Safar P, Tisherman S, Kuboyama K, Radovsky A. Beneficial effect of mild hypothermia and detrimental effect of deep hypothermia after cardiac arrest in dogs. Stroke. 1992;23(10):1454-1462.

43. Kushimoto S, Gando S, Saitoh D, et al. The impact of body temperature abnormalities on the disease severity and outcome in patients with severe sepsis: an analysis from a multicenter, prospective survey of severe sepsis. Crit Care. 2013;17(6):R271.

44. Drewry AM, Fuller BM, Skrupky LP, Hotchkiss RS. The presence of hypothermia within 24 hours of sepsis diagnosis predicts persistent lymphopenia. Crit Care Med. 2015;43(6):1165-1169.

45. Bellmann-Weiler R, Weiss G. Pitfalls in the diagnosis and therapy of infections in elderly patients - a mini-review. Gerontology. 2009; 55(3):241-249.

46. Clifford KM, Dy-Boarman EA, Haase KK, Maxvill K, Pass SE, Alvarez CA. Challenges with diagnosing and managing sepsis in older adults. Expert Rev Anti Infect Ther. 2016;14(2):231-241.

47. Inoue S, Suzuki K, Komori Y, et al. Persistent inflammation and T cell exhaustion in severe sepsis in the elderly. Crit Care. 2014;18(3):R130.

48. Diodato MD, Knoferl MW, Schwacha MG, Bland KI, Chaudry IH. Gender differences in the inflammatory response and survival following haemorrhage and subsequent sepsis. Cytokine. 2001;14(3):162-169.

49. De Maio A, Torres MB, Reeves RH. Genetic determinants influencing the response to injury, inflammation, and sepsis. Shock. 2005; 23(1):11-17.
Clinical Interventions in Aging

\section{Publish your work in this journal}

Clinical Interventions in Aging is an international, peer-reviewed journal focusing on evidence-based reports on the value or lack thereof of treatments intended to prevent or delay the onset of maladaptive correlates of aging in human beings. This journal is indexed on PubMed Central, MedLine,

\section{Dovepress}

CAS, Scopus and the Elsevier Bibliographic databases. The manuscript management system is completely online and includes a very quick and fair peer-review system, which is all easy to use. Visit http://www.dovepress. com/testimonials.php to read real quotes from published authors. 